\title{
Supplementary Information:
}

\section{Overlap Concentration in Salt-Free Polyelectrolyte Solutions}

Jonathan A. Bollinger, ${ }^{\dagger}$ Gary S. Grest, ${ }^{\dagger}$ Mark J. Stevens, ${ }^{* \dagger}$ and Michael Rubinstein*,‡

† Sandia National Laboratories, Center for Integrated Nanotechnologies, Albuquerque, NM 87185

‡ Mechanical Engineering and Materials Science, Biomedical Engineering, Chemistry, and Physics Departments, Duke University, Durham, NC 27708; Institute for Chemical Reaction Design 303 and Discovery (WPI-ICReDD), Hokkaido University, 304 N21W10 Kita-ku, Sapporo 001-0021, Japan

Table of end-to-end distance $\mathrm{R}$ as a function of the number of monomers in a chain $\mathrm{N}$ and monomer concentration c. All in Lennard-Jones units.

\begin{tabular}{cccccccc}
$\mathrm{N}: \begin{array}{c}10 \\
\mathrm{C}\end{array}$ & $\mathrm{R}$ & $\mathrm{C}$ & $\mathrm{R}$ & $\mathrm{C}$ & $\mathrm{R}$ & $\mathrm{c}$ & $\mathrm{R}$ \\
\hline 0.500 & 1.8 & 0.100 & 3.3 & 0.500 & 4.7 & 0.200 & 7.8 \\
0.300 & 1.9 & 0.050 & 3.5 & 0.300 & 5.0 & 0.100 & 8.7 \\
0.200 & 1.9 & 0.020 & 3.7 & 0.200 & 5.3 & 0.050 & 9.7 \\
0.100 & 2.0 & 0.010 & 3.9 & 0.100 & 5.9 & 0.020 & 11.3 \\
0.050 & 2.1 & 0.005 & 4.0 & 0.050 & 6.5 & 0.005 & 14.2 \\
0.020 & 2.1 & & & 0.020 & 7.3 & 0.002 & 16.3 \\
& & & & 0.010 & 7.9 & 0.001 & 17.7 \\
& & & 0.005 & 8.5 & 0.0005 & 18.8 \\
& & & 0.002 & 9.2 & 0.0002 & 20.1 \\
& & & 0.001 & 9.6 & 0.00005 & 21.4 \\
& & & 0.0005 & 10.0 & 0.00002 & 21.9 \\
& & & 0.0002 & 10.3 & 0.000005 & 22.5
\end{tabular}




\begin{tabular}{|c|c|c|c|c|c|c|c|}
\hline \multirow{2}{*}{$\begin{array}{c}N: 200 \\
c\end{array}$} & \multicolumn{3}{|c|}{400} & \multirow{2}{*}{$\begin{array}{c}800 \\
c \\
\end{array}$} & \multicolumn{3}{|c|}{1200} \\
\hline & $\mathrm{R}$ & $\mathrm{C}$ & $\mathrm{R}$ & & $\mathrm{R}$ & C & $\mathrm{R}$ \\
\hline 0.075 & 13.3 & 0.010 & 28.9 & 0.0500 & 29.6 & 0.0002 & 150 \\
\hline 0.050 & 14.4 & 0.010 & 29.0 & 0.0200 & 36.6 & 0.0002 & 151 \\
\hline 0.050 & 14.3 & 0.005 & 34.0 & 0.0050 & 49.9 & 0.00005 & 213 \\
\hline 0.020 & 17.0 & 0.005 & 34.0 & 0.0020 & 63.6 & 0.00005 & 211 \\
\hline 0.020 & 17.0 & 0.002 & 42.1 & 0.0010 & 75.1 & 0.00002 & 237 \\
\hline 0.010 & 19.5 & 0.002 & 42.2 & 0.0010 & 76.1 & 0.000005 & 269 \\
\hline 0.010 & 19.5 & 0.001 & 49.6 & 0.0005 & 90.0 & 0.000002 & 284 \\
\hline 0.005 & 22.5 & 0.001 & 49.7 & 0.0005 & 90.8 & 0.000001 & 287 \\
\hline 0.002 & 27.1 & 0.0005 & 57.8 & 0.0002 & 115 & & \\
\hline 0.0005 & 34.3 & 0.0002 & 68.8 & 0.0002 & 115 & & \\
\hline 0.0002 & 38.1 & 0.0001 & 75.9 & 0.0001 & 135 & & \\
\hline 0.0001 & 40.5 & 0.00005 & 81.6 & 0.00005 & 151 & & \\
\hline 0.00005 & 42.2 & 0.00002 & 86.8 & 0.00002 & 168 & & \\
\hline 0.00002 & 43.9 & 0.00001 & 89.7 & 0.00001 & 176 & & \\
\hline \multirow[t]{3}{*}{0.000005} & 45.6 & 0.000005 & 92.8 & 0.000005 & 183 & & \\
\hline & & 0.000002 & 93.9 & 0.000002 & 189 & & \\
\hline & & & & 0.000001 & 191 & & \\
\hline
\end{tabular}

N: 1600

\begin{tabular}{cc}
$\mathrm{C}$ & $\mathrm{R}$ \\
\hline 0.0001 & 226 \\
0.00005 & 250 \\
0.00005 & 267 \\
0.000005 & 371 \\
0.000002 & 371 \\
0.000001 & 383
\end{tabular}

